BIBECHANA

Vol. 6, March 2010

\title{
Regular Associated Solution Model for the Estimation of Heat of Mixing of Binary Liquid Alloys
}

\author{
D. Adhikari ${ }^{\mathrm{a}}$, B.P. Singh ${ }^{\mathrm{a}}$, I.S. Jha ${ }^{\mathrm{b}}$ \\ ${ }^{a}$ Univ. Dept. of Physics, T.M.Bhag. University, Bhagalpur, Bihar, India \\ ${ }^{\mathrm{b}}$ Dept. of Physics, M.M.A.M. Campus (Tribhuvan University), Biratnagar, Nepal
}

\begin{abstract}
We have determined the equilibrium constants and pairwise interaction energies between the species and the complexes of liquid $\mathrm{CuSn}, \mathrm{AgAl}$ and $\mathrm{FeSi}$, alloys on the basis of regular associated solution model. These parameters are then used to estimate the heat of mixing of each alloy. The observed asymmetry in the heat of mixing of each alloy with respect to concentration is well explained.
\end{abstract}

\section{Key Words: Free energy of mixing; Asymmetry; Binary alloys, interaction energy}

\section{Introduction}

Several models have been proposed to solve the difficulties and complexities of obtaining thermodynamic parameters. One of the models successfully used for accounts of the thermodynamic characteristics of binary liquid alloy systems, is the model of regular associated solution model. In regular associated solution model, it is assumed that strong associations among the constituent species exist in the liquid phase close to the melting temperature. These associations are given different names such as 'complexes', 'pseudomolecules', 'clusters', 'associations' etc. This assumption has been used by several researchers [1-12] to explain the asymmetry of the properties of mixing for binary alloys. Thus binary alloys in a liquid phase can be considered as a ternary mixture of unassociated atoms of components and complexes, all in chemical equilibrium. Jordan [3] proposed that activity of unassociated atoms and the complexes can be estimated by treating the mixture as a ternary system and termed this mixture as regular associated solution. Jordan [3] applied this idea in the congruently melting semiconductors $\mathrm{Zn}-\mathrm{Te}$ and $\mathrm{Cd}-\mathrm{Te}$ and determined thermodynamic equations for liquidus curve (the melting temperature against concentration curve) of these alloys. This model is further extended and applied by other researchers $[4,5,12]$ for the determination of thermodynamics and microscopic parameters of different alloy systems in molten state. In present paper, we intend to apply regular associated solution model to obtain the heat of mixing of liquid $\mathrm{CuSn}, \mathrm{AgAl}$ and $\mathrm{FeSi}$ alloys. For this, we have assumed $\mathrm{Cu}_{3} \mathrm{Sn}, \mathrm{Ag}_{3} \mathrm{Al}$ and 


\section{Adhikari et al.}

$\mathrm{Fe}_{2} \mathrm{Si}$ complexes in liquid $\mathrm{CuSn}, \mathrm{AgAl}$ and $\mathrm{FeSi}$ alloys respectively by studying their corresponding phase diagram in solid state[13].

Theoretical formalism is given in section 2, section 3 deals with the numerical result and discussion. Conclusion is provided in section 4.

\section{Theory}

Suppose there be three species in equilibrium in the liquid alloy, namely, monomers $A, B$ and $A_{p} B$ molecules in the respective concentrations $n_{A}, n_{B}$, and $n_{A p B}$ moles. Considering a solution of $n_{1}$ atoms of $A$ and $n_{2}$ atoms of $B$, the formation of $\mathrm{n}_{\mathrm{ApB}}$ complex requires $\mathrm{n}_{1}=\mathrm{n}_{\mathrm{A}}+\mathrm{pn}_{\mathrm{ApB}}$ and $\mathrm{n}_{2}=\mathrm{n}_{\mathrm{B}}+\mathrm{n}_{\mathrm{ApB}}$ for conservation of mass in the partially associated solution. When there is association, the thermodynamic behaviour of complexes $\mathrm{A}$ and $\mathrm{B}$ components is governed by their true mole fractions $\mathrm{x}_{\mathrm{A}}, \mathrm{x}_{\mathrm{B}}$ and $\mathrm{x}_{\mathrm{ApB}}$ rather than their gross mole fraction $\mathrm{x}_{1}$ and $\mathrm{x}_{2}$, where $\mathrm{x}_{1}=\mathrm{n}_{1} /\left(\mathrm{n}_{1}+\mathrm{n}_{2}\right)$ etc. and $\mathrm{x}_{\mathrm{A}}=\mathrm{n}_{\mathrm{A}} /\left(\mathrm{n}_{\mathrm{A}}+\mathrm{n}_{\mathrm{B}}+\mathrm{n}_{\mathrm{ApB}}\right)$ etc.

Using above relations, the two sets of mole fractions are related to each other by the relations

$$
\mathrm{x}_{\mathrm{A}}=\mathrm{x}_{1}-\mathrm{px}_{2} \mathrm{x}_{\mathrm{ApB}}, \mathrm{x}_{\mathrm{B}}=\mathrm{x}_{2}-\left(1-\mathrm{px}_{2}\right) \mathrm{x}_{\mathrm{ApB}}
$$

In regular associated solution solutions, the gross chemical potentials of components 1 and 2 are equal to the chemical potentials of the monomeric species A and B [14]. The activity coefficients $\gamma_{\mathrm{A}}, \gamma_{\mathrm{B}}$ and $\gamma_{\mathrm{ApB}}$ of monomers and complex can be expressed in terms of pairwise interaction energies through [3]

$$
\begin{aligned}
& R T \ln \gamma_{\mathrm{A}}=\mathrm{x}_{\mathrm{B}}^{2} \omega_{12}+\mathrm{x}_{\mathrm{ApB}}^{2} \omega_{13}+\mathrm{x}_{\mathrm{B}} \mathrm{x}_{\mathrm{ApB}}\left(\omega_{12}-\omega_{23}+\omega_{13}\right) \\
& \mathrm{RT} \ln \gamma_{\mathrm{B}}=\mathrm{x}_{\mathrm{ApB}}^{2} \omega_{23}+\mathrm{x}_{\mathrm{A}}^{2} \omega_{12}+\mathrm{x}_{\mathrm{A}} \mathrm{x}_{\mathrm{ApB}}\left(\omega_{23}-\omega_{13}+\omega_{12}\right) \\
& \mathrm{RT} \ln \gamma_{\mathrm{ApB}}=\mathrm{x}_{\mathrm{A}}^{2} \omega_{13}+\mathrm{x}_{\mathrm{B}}^{2} \omega_{23}+\mathrm{x}_{\mathrm{B}} \mathrm{x}_{\mathrm{ApB}}\left(\omega_{13}-\omega_{12}+\omega_{23}\right)
\end{aligned}
$$

where $\omega_{12}, \omega_{13}$ and $\omega_{23}$ are interaction energies for the species $A, B ; A, A_{p} B$ and $B, A_{p} B$ respectively, $\mathrm{T}$ the temperature and $\mathrm{R}$ stands for the universal gas constant. The equilibrium constant in a regular associated can be obtained [6] as

$$
\ln \mathrm{k}=\ln \left(\frac{\mathrm{x}_{\mathrm{A}}^{\mathrm{P}} \mathrm{x}_{\mathrm{B}}}{\mathrm{x}_{\mathrm{ApB}}}\right)+\frac{\omega_{12}}{\mathrm{RT}}\left[\mathrm{px}_{\mathrm{B}}\left(1-\mathrm{x}_{\mathrm{B}}\right)+\mathrm{x}_{\mathrm{A}}\right]+\frac{\omega_{13}}{\mathrm{RT}}\left[\mathrm{px}_{\mathrm{ApB}}\left(1-\mathrm{x}_{\mathrm{A}}\right)-\mathrm{x}_{\mathrm{A}}\right]+\frac{\omega_{23}}{\mathrm{RT}}\left[\mathrm{x}_{\mathrm{ApB}}\left(1-\mathrm{px}_{\mathrm{B}}\right)-\mathrm{x}_{\mathrm{B}}\right]
$$


BIBECHANA

Vol. 6, March 2010

Now using the equations listed above the integral excess free energy $\Delta G^{x s}$ is given by

$$
\begin{aligned}
\Delta \mathrm{G}^{\mathrm{xs}}= & \frac{1}{\left(1+\mathrm{px}_{\mathrm{ApB}}\right)}\left(\mathrm{x}_{\mathrm{A}} \mathrm{x}_{\mathrm{B}} \omega_{12}+\mathrm{x}_{\mathrm{A}} \mathrm{x}_{\mathrm{ApB}} \omega_{13}+\mathrm{x}_{\mathrm{B}} \mathrm{x}_{\mathrm{ApB}} \omega_{23}\right)+\frac{\mathrm{RT}}{\left(1+\mathrm{px}_{\mathrm{ApB}}\right)} \times \\
& \quad\left(\mathrm{x}_{\mathrm{A}} \ln \mathrm{x}_{\mathrm{A}}+\mathrm{x}_{\mathrm{B}} \ln \mathrm{x}_{\mathrm{B}}+\mathrm{x}_{\mathrm{ApB}} \ln \mathrm{x}_{\mathrm{ApB}}\right)-\mathrm{RT}\left(\mathrm{x}_{1} \ln \mathrm{x}_{1}+\mathrm{x}_{2} \ln \mathrm{x}_{2}\right)+\frac{\mathrm{x}_{\mathrm{ApB}}}{\left(1+\mathrm{px}_{\mathrm{ApB}}\right)} \mathrm{RT} \ln \mathrm{k}
\end{aligned}
$$

Once the expressions for $\Delta \mathrm{G}\left[=\Delta \mathrm{G}^{\mathrm{xs}}+\mathrm{RT}\left(\mathrm{x}_{1} \ln \mathrm{x}_{1}+\mathrm{x}_{2} \ln \mathrm{x}_{2}\right)\right]$ is obtained, heat of mixing can be found using standard thermodynamic relation

$$
\Delta \mathrm{H}=\Delta \mathrm{G}-\mathrm{T}\left(\frac{\partial \Delta \mathrm{G}}{\partial \mathrm{T}}\right)_{\mathrm{T}, \mathrm{P}}
$$

The pairwise interaction energies and equilibrium constant are determined by the following method:

In a regular associated solution $\mathrm{x}_{1} \gamma_{1}=\mathrm{x}_{\mathrm{A}} \gamma_{\mathrm{A}}$ and $\mathrm{x}_{2} \gamma_{2}=\mathrm{x}_{\mathrm{B}} \gamma_{\mathrm{B}}$, where $\gamma_{1}$ and $\gamma_{2}$ are respective gross activity coefficients of components 1 and 2 . Thus

$$
\ln \gamma_{1}=\ln \gamma_{\mathrm{A}}+\ln \frac{\mathrm{x}_{\mathrm{A}}}{\mathrm{x}_{1}}
$$

and

$$
\ln \gamma_{2}=\ln \gamma_{\mathrm{B}}+\ln \frac{\mathrm{x}_{\mathrm{B}}}{\mathrm{x}_{2}}
$$

the pairwise interaction energies, the equilibrium constants and the activity coefficients at infinite dilution can be written as [9]

$$
\begin{gathered}
\ln \gamma_{1}^{0}=\frac{\omega_{12}}{\mathrm{RT}} \\
\mathrm{k} \exp \left(\omega_{13} / \mathrm{RT}\right)=\frac{\gamma_{1}^{\mathrm{o}} \gamma_{2}^{\mathrm{o}}}{\gamma_{1}^{\mathrm{o}}-\gamma_{2}^{\mathrm{o}}}
\end{gathered}
$$

where $\gamma_{1}^{o}$ and $\gamma_{2}^{o}$ are activity coefficients of component $\mathrm{A}$ and that of $\mathrm{B}$ at zero concentrations.

Solving equations ( $2 a)$ and $(2 b)$ we obtain

$$
\begin{aligned}
& \frac{\omega_{13}}{\mathrm{RT}}=\frac{\mathrm{x}_{\mathrm{B}} \ln \left(\frac{\mathrm{a}_{2}}{\mathrm{x}_{\mathrm{B}}}\right)+\left(1-\mathrm{x}_{\mathrm{B}}\right) \ln \left(\frac{\mathrm{a}_{1}}{\mathrm{x}_{\mathrm{A}}}\right)-\mathrm{x}_{\mathrm{B}}\left(1-\mathrm{x}_{\mathrm{B}}\right) \frac{\omega_{12}}{\mathrm{RT}}}{\mathrm{x}_{\mathrm{ApB}}^{2}} \\
& \mathrm{\omega _{23 }}
\end{aligned}=\frac{\mathrm{x}_{\mathrm{A}} \ln \left(\frac{\mathrm{a}_{1}}{\mathrm{x}_{\mathrm{A}}}\right)+\left(1-\mathrm{x}_{\mathrm{A}}\right) \ln \left(\frac{\mathrm{a}_{2}}{\mathrm{x}_{\mathrm{B}}}\right)-\mathrm{x}_{\mathrm{A}}\left(1-\mathrm{x}_{\mathrm{A}}\right) \frac{\omega_{12}}{\mathrm{RT}}}{\mathrm{x}_{\mathrm{ApB}}^{2}}
$$

Using equations (6), (16) and (17), we can derive

$$
\ln \mathrm{k}+\frac{\omega_{13}}{\mathrm{RT}}=\left(\frac{1+\mathrm{x}_{\mathrm{A}}}{\mathrm{x}_{\mathrm{ApB}}}\right) \ln \left(\frac{\mathrm{a}_{1}}{\mathrm{x}_{\mathrm{A}}}\right)+\frac{\mathrm{x}_{\mathrm{B}}}{\mathrm{x}_{\mathrm{ApB}}}\left[\ln \left(\frac{\mathrm{a}_{2}}{\mathrm{x}_{\mathrm{B}}}\right)-\frac{\omega_{12}}{\mathrm{RT}}\right]+\ln \left(\frac{\mathrm{a}_{1}^{\mathrm{p}} \mathrm{a}_{2}}{\mathrm{x}_{\mathrm{ApB}}}\right)
$$




\section{Adhikari et al.}

\section{Results and Discussion}

To find heat of mixing of binary alloys, we have found the complex concentration in a regular associated solution of respective alloys by using equations (6), (9) and observed data of corresponding activities [13]. The complex concentration of liquid alloys in molten state are presented in table 1 . We have found the equilibrium constants and the pairwise interaction energies between the species and the complexes using equations (3), (4), (6), (7), (8), and observed data of corresponding integral excess free energies of mixing. The equilibrium constants and pairwise interaction energies of different binary alloys are listed in table 2 .

\subsection{CuSn alloys at 1400K}

It is found from the analysis that the heat of mixing is negative at all concentration. Our theoretical calculation shows that the minimum value of the heat of mixing is -4.95 $\mathrm{kJ}$ at $\mathrm{x}_{\mathrm{Cu}}=0.8$ which exactly matches with the experimental value [1]. Further it is observed that the concentration dependence of asymmetry in $\Delta \mathrm{H}$ can be explained only when one considers the temperature dependence of the pairwise interaction energies. The agreement between the calculated and experimental values is also good. The calculated and observed values of heat of mixing are compared in figure 1.

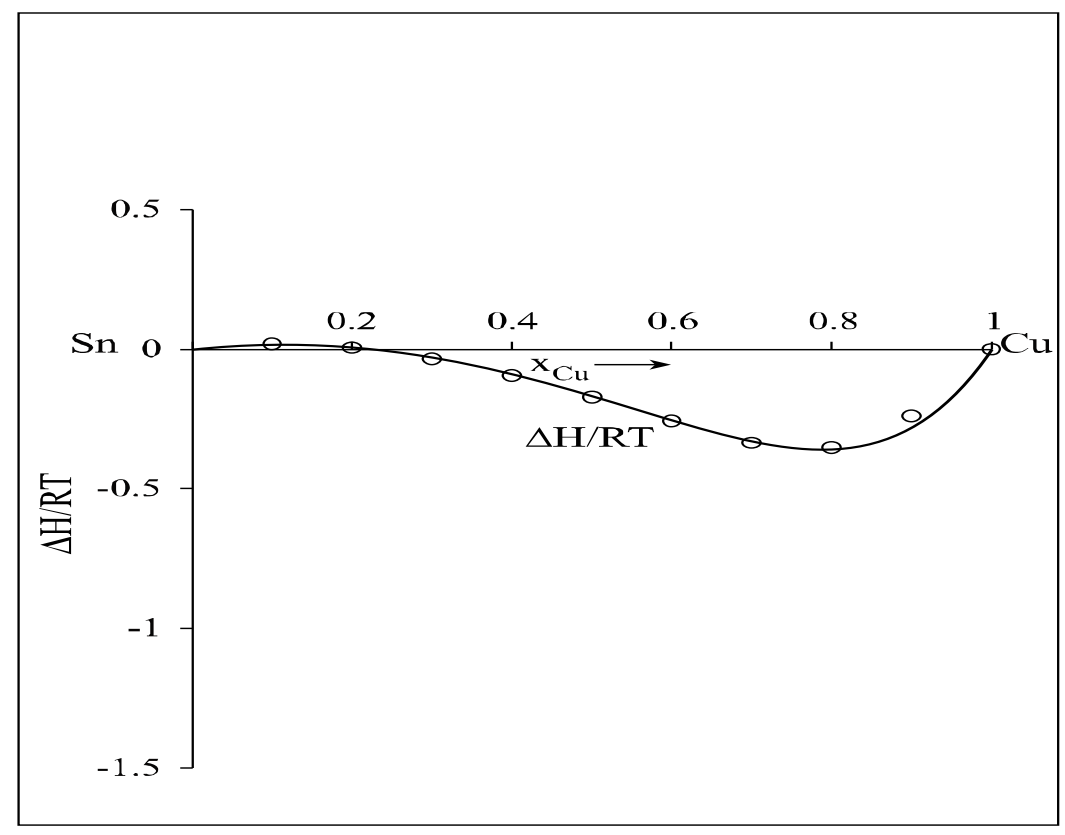

Figure-1: Free energy of mixing $(\Delta H R T)$ versus $x_{C u}$ of liquid $C u S n$ solution $(1400 \mathrm{~K}) ;(-)$ theory, $(\circ \circ \circ)$ experiment [13] 
BIBECHANA

Vol. 6, March 2010

\subsection{AgAl alloys at 1273K}

It is found from the analysis that the enthalpy of mixing is negative at all concentration, being minimum around stoichiometric composition $\left(\Delta \mathrm{H}=-0.611 \mathrm{RT}\right.$ at $\mathrm{x}_{\mathrm{Ag}}$ $=0.72$ ). Further it is observed that the concentration dependence of asymmetry in $\Delta \mathrm{H}$ can be explained only when one considers the temperature dependence of the pairwise interaction energies. The calculated and observed values heat of mixing is compared in figure 2 .

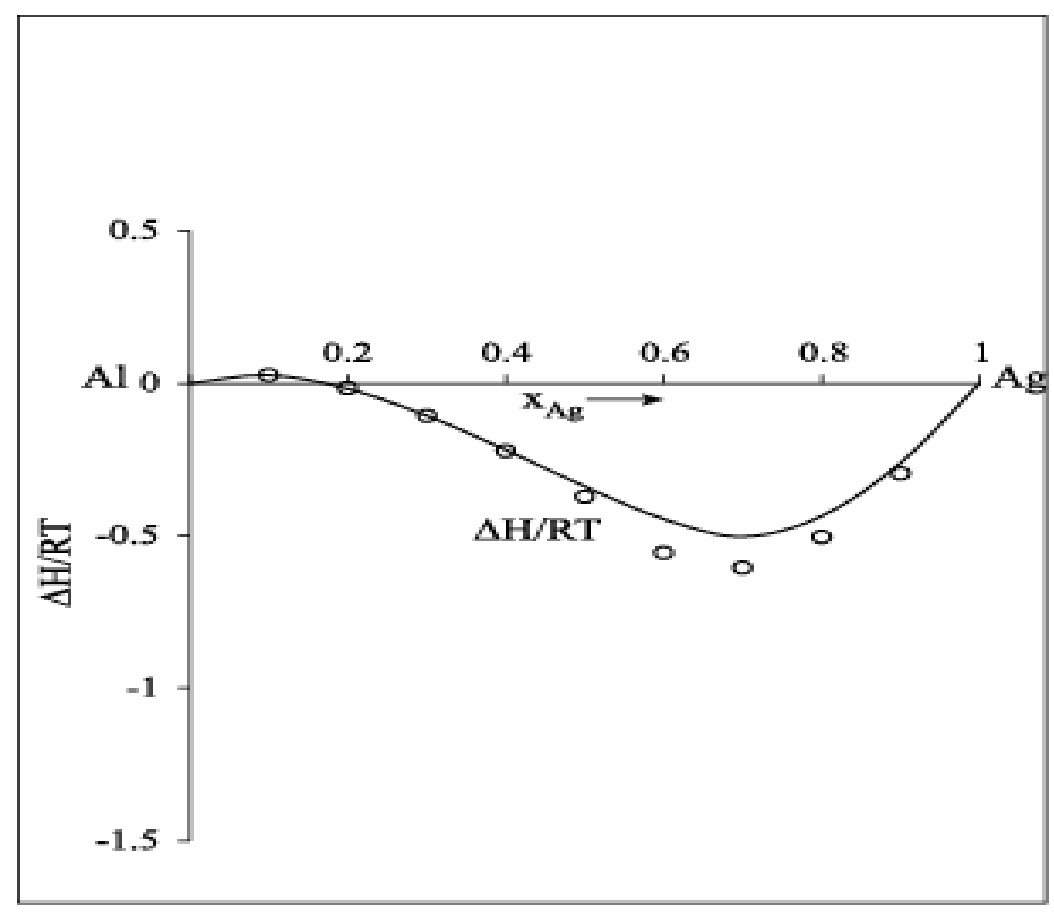

Figure-2: Free energy of mixing $(\Delta H / R T)$ versus $x_{A g}$ of liquid $A g A l$ solution $(1273 \mathrm{~K}) ;(-)$ theory, (০o०) experiment [1]

\subsection{FeSi alloys at $1873 K$}

It is found from the analysis that the heat of mixing is negative at all concentration. Our theoretical calculation shows that the minimum value of the heat of mixing is -2.585 $\mathrm{kJ}$ at $\mathrm{x}_{\mathrm{Fe}}=0.55$. Further it is observed that the concentration dependence of asymmetry in $\Delta \mathrm{H}$ can be explained only when one considers the temperature dependent of the 
D. Adhikari et al.

pairwise interaction energies. Figure 3 show the comparison between the experimental and calculated values of heat of mixing and entropy of mixing.

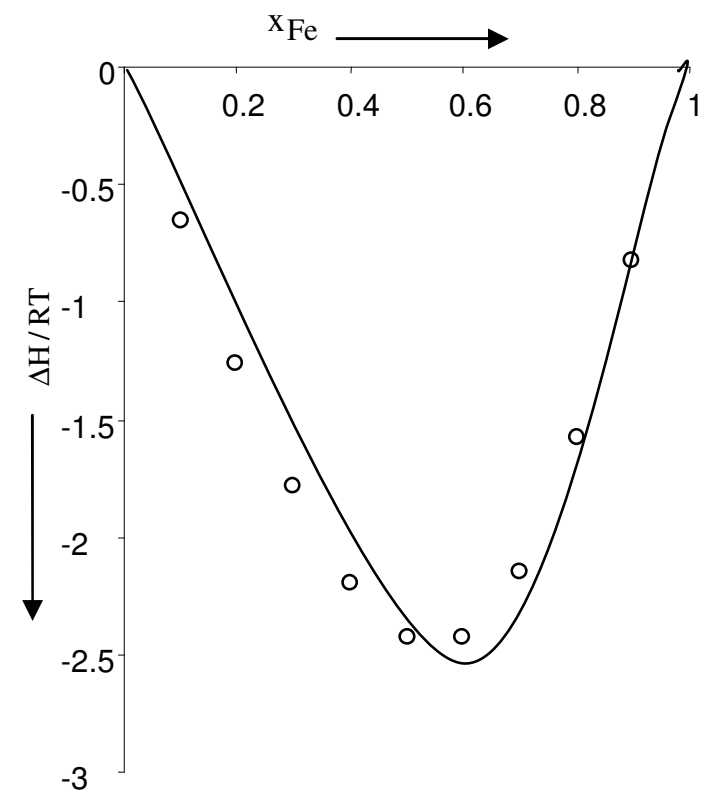

Figure-3: Free energy of mixing $(\Delta G / R T)$ versus $x_{F e}$ of liquid $F e S i$ solution $(1873 \mathrm{~K}) ;(-)$ theory, (०००) experiment [13]

Table 1

\begin{tabular}{|c|c|c|c|}
\hline$x_{\mathrm{Cu}} / x_{\mathrm{Ag} /} x_{\mathrm{Fe}}$ & $x_{\mathrm{Cu}_{3} \mathrm{Sn}}$ & $x_{\mathrm{Ag}_{3} \mathrm{Al}}$ & $x_{\mathrm{Fe}_{2} \mathrm{Si}}$ \\
\hline 0.1 & 0.001095 & 0.008257 & 0.01635 \\
\hline 0.2 & 0.008378 & 0.03075 & 0.05294 \\
\hline 0.3 & 0.02658 & 0.0656 & 0.1086 \\
\hline 0.4 & 0.05146 & 0.1138 & 0.1869 \\
\hline 0.5 & 0.08541 & 0.1803 & 0.2903 \\
\hline 0.6 & 0.1240 & 0.2517 & 0.3337 \\
\hline 0.7 & 0.1525 & 0.3075 & 0.3720 \\
\hline 0.8 & 0.1650 & 0.2355 & 0.2968 \\
\hline 0.9 & 0.1192 & 0.1056 & 0.1098 \\
\hline
\end{tabular}


BIBECHANA

Vol. 6, March 2010

Table 2

\begin{tabular}{|c|c|c|c|}
\hline \multirow{2}{*}{ Parameter } & \multicolumn{3}{|c|}{ Liquid alloy Systems } \\
\cline { 2 - 4 } & CuSn at 1400K & AgAl at 1273K & FeSi at 1873K \\
\hline $\mathrm{k}$ & 0.1652 & 0.0494 & 0.004139 \\
\hline$\omega_{12}\left(\mathrm{Jmol}^{-1}\right)$ & -13500 & -11382 & -64170 \\
\hline$\omega_{13}\left(\mathrm{Jmol}^{-1}\right)$ & -24900 & -617 & -14720 \\
\hline$\omega_{23}\left(\mathrm{Jmol}^{-1}\right)$ & -16500 & -28064 & -45500 \\
\hline
\end{tabular}

\section{Conclusion}

The regular associated solution model is found to be suitable to estimate the heat of mixing for both weakly and strongly interacting binary liquid alloys. The observed asymmetries in the heat of mixing of binary liquid alloys with respect to the concentrations are well explained on the basis of regular associated solution models.

\section{Acknowledgement}

One of the authors (D. Adhikari) is thankful to University Grant Commission (UGC), Nepal, for providing financial support to pursue the research.

\section{References}

[1] Bhatia, A.B. and Hargoove, W.H. 1974.Phys. Rev. B-10:316 .

[2] Singh, R.N. 1987. Can J. Phys. 65: 309.

[3] Jordan, A.S. 1970. Metall. Trans. 1:239.

[4] Lele, S.and Ramchandra Rao, P. 1981. Metall. Trans. 12 B: 659.

[5] Osmura, K. and Predel , B. 1977. Tans. J. Phys. Inst. Met. 18 :765 .

[6] K. Hoshino and W.H. Young, J. of Phys. F: Met. Phys. 10,1365 (1980).

[7] McAlister, S.P. and Crozier, E.D. 1974. J. of Phys. C-7:3509. 
D. Adhikari et al.

[8] Jha, I.S. ,Singh, R. N. Shrivastava ,P.L. and Mitra, N.R. 1990.Phil. Mag. 61:8445.

[9] Singh, R. N., Jha, I.S. and Pandey, D.K. 1993.J. Condens. Matter 5: 2469.

[10] Bhatia,A.B. and Singh, R. N. 1980.Phys. Letters A-78:460 .

[11] Gerling, U. Pool ,M. J. and Predel, 1983.B. Z. Metallkde 74:616 .

[12] Adhikari, D., Jha, I.S. and Singh, B. P. 2010.Physica B- 405 :1861 .

[13] Hultgren, R. Desai, P. D.,Hawkins, D.T., Gleiser, M. and Kelley, K.K. (ASM,Metal Park,1973).Selected Values of the Thermodynamic Properties of Binary Alloys

[14] Prigogine, I. and Defay, R. ,( Longmans Green and Co.London, 1974) Chem. Thermodynamicsp. 257. 